Artículos

\title{
EPISTEMOLOGÍA DEL DETALLE DESDE UNA PERSPECTIVA DEL SUR
}

\author{
Porta, Martín E.
}

Martín E. Porta

mporta@soc.unicen.edu.ar

ECCO. Facultad de Ciencias Sociales - Universidad

Nacional del Centro de la Provincia de Buenos Aires

(UNCPBA), Argentina

Intersecciones en Comunicación

Universidad Nacional del Centro de la Provincia de Buenos Aires, Argentina

ISSN: $1515-2332$

ISSN-e: 2250-4184

Periodicidad: Anual

vol. 1, núm. 15, 2021

intercom@soc.unicen.edu.ar

Recepción: 10 Marzo 2021

Aprobación: 26 Abril 2021

URL: http://portal.amelica.org/ameli/

jatsRepo/216/2161348006/index.htm

DOI: https://doi.org/10.51385/ic.v1i15.61

Intersecciones en Comunicación sostiene su compromiso con las políticas de Acceso Abierto a la información científica. Los autores conservan los derechos de autor y conceden a la revista el derecho de la primera publicación de la obra de forma simultánea bajo la Licencia Licencia Creative Commons Atribución-No ComercialCompartir Igual 4.0 Internacional que permite compartir el trabajo con el reconocimiento de su publicación inicial en Intersecciones en Comunicación. Además, se adhiere a la declaración DORA, y su propuesta mejorar la forma de evaluación científica. La revista cuenta con políticas de preservación de documentos digitales a través del Repositorio Institucional Digital de Acceso Abierto de la Universidad Nacional del Centro de la Provincia de Buenos Aires (https:// www.ridaa.unicen.edu.ar) Intersecciones en Comunicación adhiere a las normas internacionales y prácticas respecto a los aspectos éticos que deben seguirse en el proceso de publicación de artículos originales. En este sentido adhiere a lo que sugiere el Committee on Publications Ethics (https://publicationethics.org/resources/ guidelinesnew/principles-transparency-and-best-practice-scholarlypublishing)

\section{c) (i) (2)}

Esta obra está bajo una Licencia Creative Commons AtribuciónNoComercial-CompartirIgual 4.0 Internacional.
Resumen: El presente trabajo es un ejercicio de reflexión, al tiempo que una propuesta para pensar herramientas dinámicas que permitan repensar los marcos impuestos históricamente por la epistemología a los campos científicos, específicamente, al campo de la comunicación social. Por ello, nos proponemos realizar una lectura cruzada entre las producciones de Walter Benjamin y las de Boaventura de Sousa Santos, para pensar epistemologías desde y con el sur global. Sostenemos en los marcos de este trabajo que ambos autores nos indican caminos de apertura a nuevas posibilidades y que, el mismo campo de la comunicación en su novedad y dispersión, se constituye como posibilidad de introducir nuevos saberes y debates desde su lugar de "frontera" en los márgenes de la cientificidad. Lejos de ser esto un obstáculo, creemos que se constituye en una emergencia para la superación de viejas restricciones que clausuran.

Palabras clave: epistemología - comunicación - cultura experiencia - imagen -.

Abstract: DETAIL EPISTEMOLOGY FROM A SOUTHERN PERSPECTIVE. The present work is an exercise in reflection, as well as a proposal to think of dynamic tools that allow rethinking the frameworks historically imposed by epistemology to scientific fields, specifically, to the field of social communication. For this reason, we propose to carry out a cross reading between the productions of Walter Benjamin and those of Boaventura de Sousa Santos, to think epistemologies from and with the global south. We maintain within the framework of this work that both authors indicate to us paths of opening to new possibilities and that, the same field of communication in its novelty and dispersion, is constituted as a possibility of introducing new knowledge and debates from its place of "frontier" on the margins of scientificity. Far from being an obstacle, we believe that it constitutes an emergency for overcoming old restrictions that are closing.

Keywords: epistemology - comunication - cultura - experience - image - 


\title{
Apertura
}

En la actualidad, con la notoria crisis del paradigma científico capitalista técnico moderno, se vuelve prioritario repensar para transformar dichas prescripciones, aún más desde las ciencias sociales: el marco de un despliegue normativo de imposiciones externas respecto a los criterios de "cientificidad", la oposición "explicación/comprensión/interpretación", la discusión respecto a la distancia entre el objeto a conocer y el sujeto que conoce, la neutralidad valorativa, la mediación y garantía de objetividad del método, la capacidad de legalización, el equilibrio en el principio de simetría entre explicar y predecir, el estatus de la teoría, etc., pero no para abandonar la epistemología sino para ocuparla. Y, en los marcos de este trabajo como lo plantea De Sousa Santos, ocupar significará darle una nueva "vuelta de tuerca" al saber para complejizar su mirada, para no parcializar ni universalizar abstractamente, para expandir las fronteras (o romperlas), de tal modo que los saberes se entrecrucen, se multipliquen, se complementen, se hibriden. Y, también claro, para contribuir a terminar con el epistemicidio que la imposición de la ciencia moderna como saber hegemónico ha provocado en la totalidad del globo, de la mano del colonialismo, el capitalismo y el patriarcado.

\begin{abstract}
"En este sentido, las Epistemologías del Sur desafían a las epistemologías dominantes en dos niveles. Por un lado, consideran que es una tarea crucial identificar y discutir la validez de los conocimientos y los saberes que no son reconocidos como tales por las epistemologías dominantes. (...) Los conocimientos redimidos por las Epistemologías del Sur son técnica y culturalmente intrínsecos a ciertas prácticas - las prácticas de resistencia contra la opresión-. Más que conocimientos, son saberes. (...) Mientras que los conocimientos se apropian de la realidad, los saberes encarnan la realidad” (De Sousa Santos, B. 2018: 309).
\end{abstract}

Cierto es que durante todo el siglo XX se han propugnado distintos modos de abrir y repensar el conocimiento. Sin embargo, y más allá de los trabajos que se han hecho en pos de la apertura del conocimiento, siguen conviviendo distintas y contrapuestas corrientes que defienden uno u otro sentido de lo "científico" al tiempo que surgen visiones más "posmodernas" que pugnan por abjurar de todo criterio epistemológico del conocimiento científico bajo el manto de sospecha positivista o cientificista (Palma, H. y Pardo, R., 2012; Murillo, S., 2012; Díaz, E., 2012; Porta, M. 2019). Al mismo tiempo, como decía anteriormente, este modelo epistémico-científico ha provocado un epistemicidio respecto a otros saberes y modos de conocimiento, priorizando la hegemonía de un tipo de conocimiento, colonizando mentes, cuerpos, territorios, geopolíticas (De Sousa Santos, B., 2018). Es así como, mientras las jóvenes ciencias sociales definían sus criterios y centraban sus debates a finales del siglo XIX y principios del XX, la proliferación de los medios masivos de comunicación y las carreras de profesionalización periodística empezaron a delinear un campo de dominios que reclamaba en el anterior contexto social un espacio "puro" de reconocimientos y especificidades que "duplicaba" el carácter problemático de los objetos sociales vistos ahora a la luz de lo comunicacional, poniendo el foco en lo estrictamente mediático y tecnológico como su eje. En este sentido, la aparición de este novedoso campo de dominios para la reflexión no sólo se hace cargo, replicando, los presupuestos conflictivos del objeto de estudio social, la relación epistemológica entre sujetos y objetos de conocimiento, las discusiones por el/los metódo/s, etc. sino que, además, agrega el carácter conflictivo de la dependencia y dificultosa separación entre prácticas profesionales y prácticas científicas (Fuentes Navarro, R. 1999; Rivera, J. 1987) que la "pureza" positivista le reclamaba a todo intento de constitución científica como tal. La emergencia de un campo de estudios sobre lo comunicacional anclado en su nacimiento en la profesionalización periodística y la preeminencia de lo mediático por sobre cualquier otra reflexión posterior y más general sobre los procesos socio-históricos comunicacionales, evidencia otra disputa de no fácil resolución que las ciencias de la comunicación arrastrarán hasta el siglo XXI. Teoría, práctica, objeto específico u objetos diversos y transdisciplinarios, capacidad de recorte disciplinar o producción teórica secundaria desde otras disciplinas, epistemología como definición e imposición cognoscitiva o epistemología como posibilidad/imposibilidad de la que dependería la constitución misma del campo y la/s ciencia/s de la comunicación, ambigüedad teórica y falta de reflexión de los fundamentos de los procesos comunicacionales, etc. son sólo alguno de 
los problemas a los que se han enfrentando aquellos científicos que intentaron reflexionar en torno a cuáles serían las especificidades (si es que las hay) para constituir un nuevo cuerpo de conocimientos que reclaman el nombre de ciencia/s de la comunicación (Vasallo de López, 2012). La disputa misma por el "nombre” del campo de estudios: ciencias de la comunicación, ciencia de la comunicación, comunicología, comunicación social, etc. dan cuenta de la efervescencia del estado de debate y desacuerdo entre los académicos que producen sus conocimientos y reconocen dichas producciones en los límites imprecisos de este campo comunicacional (Galindo Cáceres, J. 1998, 2005). Dice Vadettaro (2015) que la comunicación misma se constituye como un oximorón (y por ende, las ciencias de la comunicación, así en plural, con este mismo criterio en tanto respuestas a preguntas sobre la pluralidad), en tanto objeto de estudios que reviste una generalidad y diversidad. "Dispersión y multiplicidad de objetos y abordajes: he aquí el desafío que implica lograr un ordenamiento de sus fundamentos, es decir, una "epistemología" (Valdettaro, S. 2015: 18). Pero no todos los autores que han reflexionado o pretenden hacerlo coinciden con esta postura. Hay quienes piensan en la imposibilidad de definir un objeto específico que constituya una disciplina (en el sentido más tradicional de definición de la ciencia) y marcan así la condena a la que se encuentra atado el campo de estudios de la comunicación. Ya no la epistemología como posibilidad sino como imposibilidad por ese mismo carácter errático y disperso, imposible de sistematización y coherencia, del que habla la autora. Otra cuestión a considerar es, entonces, no solo la discusión sobre la posibilidad o imposibilidad de una epistemología de la comunicación (y en ese sentido la posibilidad o imposibilidad de su carácter disciplinario y científico) sino además la cuestión de si es una o la conjunción de varias ciencias, si el oximorón antes mencionado por Valdettaro como central a su definición no se impone como condición en tanto imposibilidad de pensar un objeto de estudio. "Los objetos tienen fronteras cada vez menos definidas; son constituidos por anillos que se entrecruzan en tramas complejas con los demás objetos restantes, a tal punto que los objetos en sí son menos reales que las relaciones entre ellos" (De Sousa Santos, B. 2018).

Estas cuestiones antes indicadas, de no fácil solución claro está, implican un punto de revisión y reformulación desde otros marcos que consideren la ampliación de las fronteras tradicionales de lo que se ha considerado los estudios en comunicación y las prácticas comunicativas y sus vínculos con lo epistemológico (esto es, la pluralidad interna como indica De Sousa Santos), sino también la apertura e incorporación de las prácticas, saberes, experiencias, luchas que históricamente han sido descuidadas por no científicas, ocultadas o simplemente negadas para avanzar hacia una ecología de saberes (considerando la pluralidad externa). Por ello, me he propuesto reflexionar en los marcos de este trabajo sobre las posibilidades, accesos, dificultades y posibles líneas de avance hacia estos objetivos que, necesariamente, tendrán que ser revisados a la luz de la conjunción entre los distintos participantes activos en la construcción compartida del conocimiento. Una reflexión que será necesariamente acotada y dirigida, de acuerdo a la configuración del texto y del autor, y como no puede ser de otra manera, según entiendo, siempre dando cuenta del lugar de la enunciación. El supuesto de base desde el que inicio el camino dice: esta propuesta de reflexión sobre la construcción de herramientas parte del supuesto que sostiene que:

"hay en el autor (Walter Benjamin) y en su producción una teoría gnoseológica que, tomando elementos provenientes de diferentes campos y reuniéndolos en una triple dimensionalidad teórico/epistemológica/metodológica (que es, en sí misma, una única dimensión), dan cuenta de una perspectiva de la comunicación como cultura en acción que elimina la cesura entre pensamiento y política, entre investigar e intervenir" (Porta, 2012). Al mismo tiempo, la vinculación con conceptos como "ecología de saberes", "traducción intercultural” y "conceptos híbridos” propuestos desde la Epistemologías del Sur, nos deberían permitir construir otras miradas que descolonicen el conocimiento y nos permitan acceder a y desde el sur global, de manera contextuada, históricamente situada”. 


\section{SABERES SITUADOS Y PROBLEMÁTICAS CONTEXTUADAS}

El ejercicio de la reflexión surge siempre de los espacios en que nos movemos, de los entrecruzamientos y diálogos de los que participamos. Por ello, me parece importante, dejar sentado de dónde provienen las inquietudes que cruzan este trabajo. Por un lado, mi formación en comunicación en la carrera de grado y luego en la trayectoria profesional me ha llevado a reconocer distintas vertientes y discusiones en torno a qué sería esto que llamamos comunicación social, como queda dicho, todas cuestiones que hacen a lo que tradicionalmente sería el espacio de trabajo de la epistemología. Conjuntamente con ello, la organización del campo disciplinar desde el abordaje de varios entrecruzamientos "disciplinares" (por darles un nombre indicativo) ha significado un lugar marginal, fronterizo para su desarrollo que muchas veces se ha indicado como poco promisorio para la constitución de un saber científico. Desde mi punto de vista y, a partir de la vinculación de lo que propone Walter Benjamin, junto a lo que proponen las Epistemologías del Sur, creo que ese lugar de frontera es el lugar indicado para producir nuevos corrimientos que nos permitan trabajar más hacia la constitución de una ecología de saberes y propugnar otros modos de ser del saber y el conocimiento, la emancipación social y la redención cultural. Por otro lado, el trabajo docente y de investigación en cátedras que abordan los problemas de la ciencia moderna, la caracterización del conocimiento científico junto con sus crisis posteriores y las reconfiguraciones de sus "normativas" me ha llevado a producir trabajos conjuntamente con los estudiantes y con otros profesionales que siempre han significado la elaboración de preguntas y más preguntas que, al decir de Benjamin, instalan el vacío y buscan la reflexión. En este sentido, lo más importante del acto de conocer no es tanto las respuestas acabadas a las que llegamos cuanto las preguntas que nos formulamos. Entonces, partiendo desde estos dos espacios de cuestionamiento que se cruzan, propongo algunos ejes de discusión y ejercicios de reflexión desde esta idea benjaminiana del detalle, de reparar en esos objetos, situaciones, prácticas, símbolos, etc. que escenifican momentos, instantaneidades para construir sentidos colectivos y que la ciencia moderna con sus configuraciones ha despreciado por no pertinentes, particulares, subjetivas, etc. Es en la experiencia vivida y percibida con el detalle cómo se "hace carne" el saber, se vuelve política y transformación social, se subjetiviza (en el sentido de no prescindir del sujeto que conoce porque ese conocer no es abstracto y sin tiempo ni historia). Es por ello que, este será un conocer que sea una reconstrucción del saber epistemológico que dé cuenta de los modos de construcción de la memoria colectiva, evitando los modos de ser ciencia como un museo donde se busca "glosar y explicar, taxonomizar y periodizar, valorar y embellecer" (Rufer, 2018), naturalizando, universalizando y homogeneizando, produciendo epistemicidios propios del colonialismo que es otro de los aspectos a tener en cuenta en este trabajo (Smith, 2016). Como indica Rufer, el pasado y su reconstrucción histórica desde lo poético pone en evidencia su aspecto político, en el mismo sentido en que Benjamin enuncia y propugna una "deconstrucción" de lo científico no sólo desde lo conceptual sino especialmente del modo de acceso al conocimiento y de su construcción y escritura, su configuración tanto desde la recuperación de citas, textos poéticos, imágenes, etc. que vayan más allá de lo establecido canónicamente por el formato científico de comunicabilidad del saber. Como práctica sociocultural y como proceso socio-histórico, la comunicación nunca puede ser neutral, va a implicar un conocer desde el capitalismo y la modernidad pero también desde el colonialismo y el género, la raza y la clase, como forma de ordenamiento de la prácticas en pos de la justicia cognitiva y epistémica (Cumes, 2012). Por todo ello, es que indicábamos más arriba que lo conceptual es al mismo tiempo en los marcos de este trabajo, metodológico, histórico y político, ético y científico. Y, por ello, este texto estará cruzado por diversas voces sin sentir la necesidad (muy benjaminiana por cierto) de poner al lector sobre aviso.

Consideraré también hipótesis de trabajo, una más que se suma a la discusión y no como una "verdad" que, el comunicador (y evitaré la nominación comunicólogo con sus cargas normativas pertinentes), como un investigador social, como un profesional de las prácticas comunicativas sociales, es un exégeta que se afana por hacer presente un sentido profundo y oculto de la realidad social. Un sentido que es producto 
de las relaciones sociales que van construyendo y reconstruyendo históricamente a la misma en los procesos colectivos y que ha sido opacado por la superficie ideológica que se constituye a través del sentido común. Se trata de romper y hacer estallar pera reconstruir y constelar. De otro modo, se tiende a la esencialización de los objetos, de subjetivándolos, como si la vida, la experiencia y, también la ciencia, no fueran el producto de ese acontecer social relacional. Es un exégeta a tientas, constructor de mapas en la oscuridad (como dice Jesús Martín Barbero, 2000) y eso, no es una debilidad, es una fortaleza si se sabe considerar como el espacio de posibilidades y reconfiguraciones para construir con otros y no desde los otros, extractivistamente. Es por ello, que me interesa aquí más reflexionar sobre el cómo y con qué medios podemos producir conocimientos con otros, abrir los muros desde las fronteras, más que entrar en el debate de si es posible o no la epistemología de la comunicación o la comunicación como disciplina en el sentido tradicional, ambas discusiones que, como queda dicho anteriormente, se relacionaban con un tipo de concepción de la epistemología de principios del siglo XX, con imposiciones normativas externas, con definiciones de objetos recortados, precisos y, que exceden por mucho, en su reconstrucción los límites de este trabajo. En este sentido, desde este texto, me propongo aportar al debate para ocupar la epistemología (al decir de Boaventura de Sousa Santos), reconociendo que todo saber científico tiene en la epistemología y en la reflexión sobre las condiciones de su producción un elemento central de su ser en el campo disciplinar. La misma palabra "epistemología" tiene que ser, entonces, liberada de las cargas negativas a las que se la ha asociado como imposiciones o reglas a cumplir y, por ello, muchas veces rechazada, descuidando con ello la reflexión profunda.

\section{DENKBILDER, DETALLES Y ECOLOGÍA DE SABERES}

Intentar producir reflexiones y marcar algunos ejes como herramientas posibles para conocer y producir saberes con otros, desde Walter Benjamin, necesariamente implica ser parcial, apuntalar unas heurísticas y dejar otras para luego, imposible sistematizar a Benjamin porque él mismo no lo hubiera querido. No hay receta, no hay unos ingredientes primarios y otros secundarios, unos esenciales y los demás superfluos. Pero siempre hay que iniciar el camino por algún lado. Decir entonces que para Benjamin "el método es una digresión" porque él es un investigador de la realidad y se basa en su propia experiencia. Al igual que los niños que están tan poco preocupados por el mundo que los adultos han conformado para ellos, por la multitud de juguetes que les compran y que han sido pensados para su entretenimiento, que juegan e imaginan un mundo con desperdicios, desechos, elementos de descarte, detalles. Esos que el mundo normal ignora y que ellos recuperan.

\footnotetext{
"Pues de hecho, los niños tienden de modo muy particular a frecuentar cualquier sitio donde se trabaje a ojos vistas con las cosas. Se sienten irresistiblemente atraídos por los desechos provenientes de la construcción, jardinería, labores domésticas y de costura o carpintería. En los productos residuales reconocen el rostro que el mundo de los objetos les vuelve precisamente, y solo, a ellos. Los utilizan no tanto para reproducir las obras de los adultos, como para relacionar entre sí, de manera nueva y caprichosa, materiales de muy diverso tipo, gracias a lo que ellos elaboran” (Benjamin, W. 1987: 25).

Por eso, Benjamin propone como método dialéctico de la nueva historiografía experimentar el presente como el mundo de la vigilia de ese sueño que es el pasado. Porque los elementos de sueño y vigilia, de redención de esos sueños de la humanidad a través de los objetos de la cultura, son parte del conocer benjaminiano. Y por eso recurre al modo en cómo los niños se relacionan con el mundo porque ellos crean sentidos sobre objetos y relaciones que nadie les pensó, que salen de su propia experiencia y percepción, del juego, de ese vínculo con el detalle. La humanidad tiene que ser como esos niños, no en el sentido iluminista de carencia de adultez, sino como expresión de esa capacidad de constelar sentidos entre cosas y relaciones que aparentemente no tienen un sentido. Porque es el modo de escapar de las configuraciones burguesas del capitalismo y también del colonialismo. Es ese modo que, desde abajo dice De Sousa Santos, se recrean saberes olvidados, sujetos al exterminio, al descarte del capital. Y por ello, ésta es una epistemología de la irrupción. El objeto está ahí; ha estado siempre. Sólo que nunca ha sido mirado. Nunca se ha interpuesto en la línea de mirada del sujeto paseante al modo como se interponen las imágenes del inconsciente ante la consciencia despreocupada. Ha irrumpido. Ha entorpecido el ver para mirar. Ha obstaculizado para descubrir. El detalle se vuelve revelador. Se interpone, se presentifica, pero no al modo del ser independiente frente a un sujeto, sino mostrando su total dependencia respecto a él para que así se pueda rememorar, remontarse en las líneas contrapuestas
} 
de los tiempos posibles, de los encuentros posibles, de las significaciones posibles. Mirada y detalle se encuentran porque éste se le hace evidente a aquella pero, aquella, le reconoce y le mira. Deja de negarlo en el ver desapasionado y, casi sin quererlo (o queriéndolo) se encuentra inmersa en un mar de sentido en el que todo está aún por descubrirse. La mirada se ha detenido en el objeto presente y ese detenimiento recupera el detalle, al mismo tiempo que descubre un vacío. El vacío de la pregunta, de la creación del sentido. Así, como el ángel de la historia, ese hereje que hace el futuro de espaldas, el paseante se dispone a configurar los sentidos dispersos en los que estalla el presente, en los que el detalle se encuentra con el todo, recuperando la historia y rearticulando la cultura de lo imposible, sobre las ruinas. El presente busca el pasado para resurgir, y éste se libera en el encuentro con el presente, camino al futuro, siempre como horizonte. Así, todo cierra para abrirse, el presente y el pasado se encuentran pero sólo para producir un conocimiento que ilumine la historia pero también el porvenir. No hay utopía sin historia. No hay historia sin utopía.

"Primeros Auxilios

De golpe pude abarcar con la mirada un barrio totalmente laberíntico, una red de calles que durante años había yo evitado, el día en que un ser querido se mudó a él. Era como si en su ventana hubieran instalado un reflector que recortara la zona con haces luminosos" (Benjamín, W. 1987: 49).

“...La utopía se basa en dos condiciones: una nueva epistemología y una nueva psicología. En cuanto a la nueva epistemología, la utopía rechaza el cierre del horizonte de expectativas y de posibilidades, y crea alternativas; en cuanto nueva psicología, la utopía rechaza la subjetividad del conformismo y crea la voluntad de luchar por alternativas. La nueva epistemología y la nueva psicología anunciadas por la utopía residen en la arqueología virtual del presente. Entiendo esta arqueología en sentido literal, pues encara el presente como un campo de excavaciones. Pero la entiendo también en sentido virtual, pues su objetivo es excavar únicamente donde nada fue realizado y descubrir por qué, o sea, por qué razón las alternativas dejaron de serlo. En este caso, la excavación se interesa por los silencios, por los silenciamientos y por las cuestiones que quedaron por preguntar" (De Sousa Santos, B. 2018: 78).

Parte de esta nueva epistemología que exploro, en compañía de Benjamin y de Boaventura o, mejor dicho, con sus guías y sapiencias, indaga sobre los modos en que a partir del shock visual se pone en movimiento el motor investigativo y de las conexiones "sin sentido" que la misma propone. Sobre los modos cómo este disparador visual es un modo del conocer comunicacional porque busca recrear sentidos allí donde aparentemente no hay nada, donde el no ser, la no existencia y el vacío cunden por doquier y la única posibilidad consistiría en llenar de un otro que es extraño, abstracto, que no repercute en las experiencias colectivas porque no les pertenece. Walter Benjamin buscaba la redención de los oprimidos discutiendo el "saber marxista" que con su sola incorporación liberaría la conciencia; discusión e intervención que va desde el detalle a las luchas, de las luchas al detalle, de la parte al todo y a la inversa, de la ciencia a la política. Boaventura llamaría la atención en que la co-presencia de las luchas y el shock tienen que hacer visible no sólo las luchas y la opresión del lado metropolitano de la línea abisal (como puede ser el caso de la discusión e intento de propugnar nuevos modos de conocer en el campo científico), hay que saltar la línea para derribarla, suprimirla (aunque en las actuales condiciones sea poco probable) para hacer emerger por las sociología de las emergencias esos otros seres no existentes que han sido confinados a la invisibilidad como descarte. Por ello, me parece importante llamar la atención sobre estos puntos, porque el detalle, los invisibilizados, los niños, pueden ver y hacer surgir la magia de lo oculto, el saber por tanto tiempo negado para la transformación, la redención, la emancipación. Walter Benjamin nos guía en la búsqueda y en las interrogaciones. Boaventura, también. No así en las respuestas. Esas quedan abiertas a la historia que multiplica y superpone los detalles para construir constelaciones de la totalidad significativa, en la pluralidad de voces y estilos, formatos y pliegues, collages de esquirlas que pueden constituirse en una nueva pieza de arte como rearticulación significativa y productiva de relaciones históricamente situadas.

El shock revela la imagen. Pero toda imagen, además de ser captada en su instantaneidad, como todo saber para poder ser preservado de su destrucción o eliminación definitiva, tiene que poder ser comunicado, dicho, expresado. Denkbilder define esa producción comunicativa en tanto que, como mediación entre sujeto y objeto, es al mismo tiempo esa mediación para captar y fijar en un instante una imagen dada inserta en el tiempo. Y es, por ello mismo, primera persona del que enuncia en breves formatos para poder comunicar sin perder la instantaneidad ni el flash de la imagen. Textos cortos, antiformas, metáforas y octavillas, para poder 
ser significativa como riguroso intercambio entre acción y escritura, dirá Benjamin en "Gasolinera”, el primer texto de Dirección Única. Extractos de paisajes, recorridos por la ciudad, caminos sinuosos del conocer que se dibujan y se pierden pero que, en su captación rápida y de flash, reúnen en sí un cúmulo de elementos que formatean un collage de sentidos para el paseante. Como quedó dicho, al investigador lo considero un exégeta, un flâneur dirá Benjamin, un holgazan que con su no productividad protesta contra la industrialización y el consumo masivo. De los investigadores se espera que produzcan mucho y en abundancia pero, raras veces o nunca, se mira la densidad de esa producción porque importa más el cuánto que el qué, el cómo. Y entonces, es ahí donde es posible intervenir, hacer saltar el continuum del trabajo capitalista en serie como línea de montaje del conocimiento al que la ciencia contribuyó como aporte al capital y el capitalismo configuró para la ciencia. Y, también, eso tiene un precio que hay que pagar. Como las propias obras de Benjamin, como las de Boaventura muchas veces, los objetos culturales no se heredan todos de la misma manera, son también producto de la historia, de la cultura burguesa y capitalista, colonialista, patriarcal. No es casualidad que los textos "más prolijos" de Benjamin hayan sido los que los intelectuales que "lo recuperan" hayan incluido al acervo de la producción intelectual: "Sobre algunos temas en Baudelaire" (en su tercera edición "purificada" de todos los errores y oscuridades, según Adorno), "La obra de arte en la época de la reproductividad técnica" y poco más de la inmensa producción benjaminiana. Por ello este texto mío cita, en exclusividad para esta exposición, "Dirección Única", el texto que Benjamin consideraba más científico de todos los que había escrito y que los intelectuales solo ven como dispersión, pequeñas poéticas desarticuladas e inconexas, no casualmente falto de cientificidad. Un pequeño aporte, desde la selección de este autor, para resituar la mirada en la vinculación entre lo que consideramos científico y el modo en que esos sentidos se construyen desde lo que se hereda culturalmente o no.

Denkbilder da cuenta además de otra cuestión central para esta reflexión. Habla no sólo de esa capacidad de captar el instante en texto, en comunicación. Da cuenta también de la incompletud, de lo no terminado, de la obra inacabada. Esa apertura a la pregunta se expresa también en el no cierre, no síntesis final. Shock que el lector tendrá que llenar con su propia producción, con su abandono del lugar pasivo frente al texto cuando el autor le indica todos y cada uno de los sentidos posibles de su escritura y ambos sienten la tranquilidad de que uno va a ser interpretado como se debe y como lo espera y, él otro, que está interpretando correctamente y que entiende lo que lee. Benjamin va a desafiar esa capacidad con las citas, el collage, la superposición y la yuxtaposición de obras inconexas, formatos breves, imágenes alternas, producciones múltiples para romper el formato académico tradicional pero, al mismo tiempo, para dejar abierto, para que el tiempo ahora se inmiscuya desde la experiencia del lector en el texto del autor, haciendo horizontes posibles entre presente y pasado. Metáfora por excelencia de ello es el denominado "Libro de los Pasajes" que, como dicen los compiladores, Benjamin no llegó a concluir por su muerte pero que yo diría y me preguntaría, si alguna vez hubiera concluido aunque hubiera seguido viviendo. Un cúmulo de citas, imágenes, recortes, experiencias narradas, percibidas, que solo contribuían al progreso de la yuxtaposición del coleccionista que amontona sin preguntarse cuándo acabará.

"Reloj Regulador

Para los grandes hombres, las obras concluidas tienen menos pesos que aquellos fragmentos en los cuales trabajan a lo largo de toda su vida. Pues la conclusión sólo colma de una incomparable alegría al más débil y disperso, que se siente así devuelto nuevamente a su vida. Para el genio, cualquier cesura, no menos que los duros reveses de fortuna o el dulce sueño, se integran en la asidua laboriosidad de su taller, cuyo círculo mágico él delimita en el fragmento. "El genio es laboriosidad" (Benjamín, W. 1987: 19).

"La transgresión metodológica repercute en los estilos y los géneros literarios, que presiden la escritura científica. La ciencia posmoderna no sigue un estilo unidimensional, fácilmente identificable; su estilo es una configuración de estilos construida según el criterio y la imaginación personal del científico. La tolerancia discursiva es el otro lado de la pluralidad metodológica" (De Sousa Santos, B. 2018: 62). 


\section{SABERES, COMUNICACIÓN, TRADUCCIÓN}

Dice Boaventura que "el objetivo de la ecología de saberes es, por un lado, explorar concepciones alternativas internas al conocimiento científico, (...) y, por el otro, proseguir con la interdependencia entre los conocimientos científicos producidos por la modernidad eurocéntrica y otros conocimientos no científicos" (De Sousa Santos, B. 2018: 29),dando cuenta de ese modo de la construcción colectiva de los saberes para desarrollar constelaciones más ricas de significado y, al mismo tiempo, híbridas, que permitan el reconocimiento de distintos modos de conocer que no son ni mejores ni peores, son complementarios dada la complejidad de la experiencia vital de los seres humanos, de la interacción entre nosotros a ambos lados de la línea abisal hasta que ésta finalmente pueda desaparecer. Un pensamiento utópico por cierto pero, como también indica Benjamin, sin utopía no hay historia y se trata de correr los marcos de la imaginación de lo posible para transformar el mundo, redimirlo. Por ello, la reflexión de este trabajo gira en torno no sólo a lo epistemológico como problema, también a la comunicación como problema, a la rearticulación de las prácticas comunicativas más allá de los medios masivos y las tecnologías. De este modo, el abanico se abre a múltiples posibilidades, cobra visos de realidad la idea que enuncia que sin comunicación no hay sociedad porque ella está en la base de esa posibilidad hermenéutica con la que todos nosotros interpretamos el mundo en el que vivimos, las experiencias por las que atravesamos y, también, las luchas en pos de la transformación del mundo y de la visión impuesta y heredada. Un proceso de construcción constante de esa posibilidad de "hermenéutica diatópica" en palabras de Boaventura, como un modo de poner en contacto horizontes humanos, tradiciones y posiciones culturales, un "diálogo dialógico" dice, que al mismo tiempo vincula la ecología de saberes, la comunicación, las prácticas comunicativas y la traducción intercultural como “proceso vivo de complejas interacciones entre artefactos heterogéneos, lingüísticos y no lingüísticos". Por ello quise recuperar la mención que hace Boaventura de la noción de traductibilidad en Benjamin, en tanto reconocimiento de una diferencia y motivación para ocuparse de ella porque me parece que abre horizontes hacia objetos/procesos de conocimiento como ampliación de un campo de conocimientos comunicacional pero, al mismo tiempo, como diálogo entre diferentes campos de saber que se articulan social y culturalmente en la vida cotidiana.

\footnotetext{
"La traducción posibilita la inteligibilidad mutua entre experiencias sociales del mundo culturalmente diversas, tanto las ya existentes como otras posibles, de acuerdo con la sociología de las ausencias y la sociología de las emergencias. Al acentuar la posibilidad de la comunicación intercultural, la traducción socava la idea de culturas originales o puras, y subraya la de relacionalidad cultural. Conceptos como equívoco, ambivalencia, mestizaje o hibridación y mimetismo, son fundamentales en la traducción intercultural” (De Sousa Santos, B. 2018: 274).
}

"La fuerza de una carretera varía según se la recorra a pie o se la sobrevuele en aeroplano. Así también, la fuerza de un texto varía según sea leído o copiado. Quien vuela sólo ve cómo la carretera va deslizándose por el paisaje y se desdevana ante sus ojos siguiendo las mismas leyes del terreno circundante. Tan solo quien recorre a pie una carretera advierte su dominio y descubre cómo en ese mismo terreno, que para el aviador no es más que una llanura desplegada, la carretera en cada una de sus curvas, va ordenando el despliegue de lejanías, miradores, calveros, y perspectivas como la voz de mando de un oficial hace salir a los soldados de sus filas. Del mismo modo, sólo el texto copiado puede dar órdenes al alma de quien lo está trabajando, mientras que el simple lector jamás conocerá los nuevos paisajes que, dentro de él, va convocando el texto, esa carretera que atraviesa su cada vez más densa selva interior: porque el lector obedece al movimiento de su Yo en el libre espacio aéreo del ensueño, mientras que el copista deja que el texto le dé ordenes. De ahí que la costumbre china de copiar libros fuera una garantía incomparable de cultura literaria, y la copia, una clave para penetrar en los enigmas de la China" (Benjamin, W. 1987: 21 y 22).

Desde mi punto de vista, entonces, se puede reflexionar como queda dicho sobre los procesos de comunicación como cultura en acción, en tanto que, las prácticas comunicativas como prácticas sociales y culturales implican intervención en la realidad y, con ello poner en evidencia el carácter relacional de las prácticas comunicativas (no puede ser un proceso simplemente monologal), es cultural como interacción entre prácticas, sujetos, objetos, artefactos, sentidos, es político. Lo central es el punto de vista de abordaje 
y construcción colectiva, la perspectiva o mirada particular, contextuada, histórica, con que se reconstruyen como objetos/procesos, los mapas para cartografíar saberes y complejizar los accesos, cómo traducir. La noción de experiencia benjaminiana es fundamental ya que, ésta, excede simplemente lo lingüístico y abre el juego a la vivencia, a los sentimientos, a la comprensión, a la intención, teniendo en cuenta el carácter intersubjetivo de la comprensión, de los lenguajes, de los sentidos (no hay lenguaje privado, dice Wittgenstein), asociada a la tradición, a la historia pero también a la utopía y a los nuevos horizontes posibles. Ya que, según Boaventura, se trata de romper también con la linealidad del tiempo (un tiempo ahora, diría Benjamin), que se asienta en la "copresencia radical" en tanto que "las prácticas y los agentes de ambos lados de la línea abisal son contemporáneos siempre y cuando haya más de un tipo de contemporaneidad”, equiparando "simultaneidad contemporaneidad, lo cual solo se puede conseguir si se abandona la concepción lineal del tiempo" (De Sousa Santos, B. 2018: 233). Finalmente, el carácter asistemático de las prácticas comunicativas es ocasión de innovación (¿creación?). "Tengo las alas prontas para alzarme, Con gusto vuelvo atrás, Porque de seguir siendo tiempo vivo, Tendría poca suerte” (GERHARD SCHOLEM: GrussvomAngelus citado en Benjamin, W. 1973: 183).

\section{IN - CONCLUSIONES}

No hay receta, no hay camino, hay mapas en la oscuridad. "Hoy en día, nadie debe empecinarse en aquello que <sabe hacer>. En la improvisación reside la fuerza. Todos los golpes decisivos habrán de asestarse como sin querer" (Benjamin, W. 1987: 21). Siempre sin perder de vista que la pluralidad a conquistar, la apertura del conocer que se instala con la pregunta constante, tiene que evitar las clausuras, los cierres definitivos que sólo limitan, monologan, dogmatizan y transforman en verdades eternas y únicas, universales, particularidades que expresan puntos de vista que, como indica su propia definición, no son más que vistas tomadas de un punto. El problema es que el punto se esconde para que la vista se evidencie como única y de todos, ocultándose así lo político del conocer.

Los saberes encarnan la realidad mientras que los conocimientos se la apropian, dice Boaventura. Los saberes encarnan la realidad porque encarnan la historia, las luchas y la opresión y sólo desde esas ruinas, desde esos silenciamientos históricamente construidos durante tanto tiempo es posible reconstruir desde abajo para constelar igualdades en las diferencias, abrirse a la vida y a la experiencia para poder reconfigurar también la ciencia. La ciencia moderna ha construido su modo de ser desde el epistemicidio, el distanciamiento, la abstracción, la objetivación del conocer al tiempo que de subjetivaba a quien producía ese conocer. Hoy en día se requiere volver a recuperar al sujeto, a los sujetos como personas, como colectividades que, desde sus propias luchas que evidencian la injusticia y la marginación, el sufrimiento humano, la vida misma, puedan articular procesos históricos nuevos más allá de las dicotomías y distanciamientos producidos para recuperar al ser. Dice Benjamin que allí donde la Historia con mayúsculas ve el progreso, el ángel de la historia, ve ruinas sobre ruinas, despojos, destrucción; donde el conocimiento metropolitano ve cultura y civilización, él ve barbarie, muerte y destrucción. Por lo tanto, no es posible reconstruir sin tener en cuenta lo que se ha destruido, no es posible reconciliar sin conciliar, tomar las ruinas y los detalles, reflexionar cómo desde ellos es posible constelar colectivamente y abrir, traducir, experimentar, saber y ser, intervenir. Y es por eso que no solo se trata de producir nuevas constelaciones de saberes y ecologías, de traducir sino también, como indica Boaventura y Benjamin, cómo y en qué condiciones, cómo hacer que aquello que ha estallado en pedazos y se nos aparece como dispuesto a unir en las diferencias se comunica sin dar lugar a que se pierda el instante del shock en el maremoto de la historia. Por eso son tan importantes las preguntas y los modos en cómo se comunica y traduce aquello nuevo que se está produciendo. Formatos, yuxtaposiciones, collages, imágenes, pequeños textos, citas y más citas, sentidos que se multiplican y reclaman del lector, pero también del copista, que siga constelando activamente con otros y otras para otros y otras. Y ya no es solo el texto académico, científico, predictivo y prefigurado el único válido para comunicar el saber, las proposiciones formales que 
nada tienen que ver con la vida de los pueblos. Es en los modos de ser y saber de esos mismos pueblos, y articulando con los modos de ser y saber de la nueva ciencia, como se puede generar una comunicación nueva para tiempos nuevos, desde el arte y la poesía, desde la metáfora y la analogía, desde los textos libres y las imágenes. Como indicaba Hans Georg Gadamer (2002) es necesario devolverle el valor de verdad al arte para que pueda decir y decirnos con verdad en estos nuevos tiempos en que la utopía tiene que dejar de ser simple ficción de la imaginación para pasar a ser parte de los nuevos modos de imaginar horizontes siempre posibles y abiertos.

Y entonces, ¿Cómo producir estos corrimientos de fronteras de lo posible para construir nuevos modos de saber y repensar los marcos de lo científico en relación comunicativa colectiva? ¿Podemos construir epistemologías otras, pluralistas, abiertas, con tiempos de simultaneidad contemporaneidad más allá de lo impuesto como hegemónico? ¿Cómo hacer saltar el continuum de la historia, como esos relojes detenidos en el contexto de la revolución, para percibir y experimentar los saberes sin que conocer implique una apropiación extractivista epistemicida? Si los objetos culturales se heredan históricamente y no todos por igual, ¿cómo hacer que los silencios hablen y las ausencias se manifiesten, que, más allá de las jerarquías propias de las luchas, tengamos acceso y podamos apropiarnos interculturalmente de las ruinas para construir el presente y el futuro? ¿Cómo contribuir a modificar las imposiciones visuales impuestas desde la monocultura cientificista para dejar paso al diálogo, el entrecruzamiento y la hibridación que enuncien y nos permitan la vivencia de la complejidad de lo real y de la relaciones humanas? He aquí algunas de las preguntas que se instalan en el vació para buscar las respuestas. He aquí los disparadores que me surgen hoy y en este momento histórico para seguir pensando y que se articularán a otras que, en los procesos de lucha, modificación y diálogo iremos generando colectivamente para poder representarnos el mundo de acuerdo a nuestras propias experiencias de ese mundo.

\section{ReFERENCiAS}

(1973) Discursos interrumpidos. Madrid: Taurus.

(1987) Dirección Única. Buenos Aires: Taurus Ediciones.

Cumes, A. (2012) "Mujeres indígenas, patriarcado y colonialismo: Un desafío a la segregación comprensiva de las formas de dominio", Revista Anuarios de Hojas de Warmi. Disponible en http://revistas.um.es/hojasdewarmi/ article/view/180291.

De Sousa Santos, B. (2018) Construyendo las Epistemologías del Sur. Antología Esencial. Volumen I y II. Buenos Aires: CLACSO.

Fuentes Navarro, R. (2012) "La investigación de la comunicación en América Latina: condiciones y perspectivas para el siglo XXI” en Revista Diálogos de la Comunicación N 56 . FELAFACS.

Gadamer, H. (2002) Verdad y Método I y II. Madrid: Biblioteca de Filosofía. Editora Nacional.

Galindo Cáceres, J. (1998) Técnicas de investigación en sociedad, cultura y comunicación. México: Addison Wesley Longman. PEARSON Educación Latinoaméricana.

(2005) Hacia una Comunicología posible. San Luis Potosí: Universidad Autónoma de San Luis Potosí.

(2000) Oficio de Cartógrafo. Travesías Latinoamericanas de las Comunicación en la Cultura. Santiago de Chile: Fondo de Cultura Económica.

Murillo, S. (2012) Prácticas científicas y procesos sociales. Una genealogía de las relaciones entre ciencias naturales, ciencias sociales y tecnologías. Buenos Aires: Editorial Biblos.

Palma, H. y Pardo, R. (2012) Epistemología de las ciencias sociales. Perspectivas y problemas de las representaciones científicas de lo social. Buenos Aires: Editorial Biblos. 
Porta, M. (2012) "Perspectiva inconclusa. Un acercamiento entre epistemología y comunicación desde Walter Benjamin” en Revisa Intersecciones en Comunicación. Año 6. Número 6. Ciclo 2012. (Págs. 11-25) Olavarría: Facultad de Ciencias Sociales - UNICEN.

Porta, M., Marmissolle, G. y Sterki, M. (2016) Cuadernos de Cátedra: "Ciencia y Sociedad”. Olavarría: Facultad de Ciencias Sociales - UNICEN.

Rivera, J. (1987) La investigación en comunicación social en Argentina. Buenos Aires: Punto Sur Editores.

Rufer, M. (2018). "La memoria como profanación y como pérdida", A contracorriente, 15 (2), 149-166.

Smith, L. (2016) "Entendiendo correctamente la historia, contando bien la historia: activismo indígena, investigación indígena”, en A descolonizar las metodologías: investigación y pueblos indígenas. Santiago: Lom ediciones.

Valdettaro, S. (2015) Epistemología de la Comunicación. Una introducción crítica. Rosario: Universidad Nacional de Rosario.

Vasallo De López, I. (2012) "La investigación de la comunicación: cuestiones epistemológicas, teóricas y metodológicas” en Revista Diálogos de la Comunicación N 56. FELAFACS. 